\title{
O POETA DO ZIFERIS: ESOTERISMO E COMUNICAÇAO SECRETA NA OBRA DE GIAMBATTISTA DELLA PORTA 1
}

\section{THE ZIFERIS' POET: ESOTERICISM AND SECRET COMMUNICATION IN THE OPUS OF GIAMBATTISTA DELLA PORTA}

\author{
Francisco de Paula Souza de Mendonça Júnior²
}

RESUMO: Buscamos discutir de que maneira Giambattista della Porta lidou com a chamada comunicação secreta dentro de suas obras conhecidas como De Magiae Naturalis e De furtivis Literarum Notis vulgo De Ziferis - Libri III, considerando as relações desse homem com a chamada magia natural. Dessa forma, as fontes são analisadas considerando a importância que a concepção de um universo regido por relações simpáticas ocultas teve sobre a ideia de segredo vigente durante os séculos XV e XVI, e questionando se houve um diálogo entre correntes esotéricas como a cabala e o hermetismo e a concepção dos mecanismos pensados por Della Porta para a utilização nas técnicas de comunicação secreta. Lembrando que tais técnicas de segredo estiveram no seio da passagem do regimen medieval para o Estado moderno, como ferramentas empregadas pelos secretários em seus esforços para a proteção do poder principesco, que de instrumento para a salvação das almas passava a ser algo cujo fim repousava em si mesmo.

PALAVRAS-CHAVE: Giambattista della Porta; Comunicação Secreta; Magia.

ABSTRACT: This communication discusses how Giambattista della Porta handled the so-called secret communication within their works known as Magiae Naturalis and De furtivis literarum Notis vulgo De Ziferis - Libri III, considering the relation of this man with the so-called natural magic. Thus, the sources are analyzed keeping in mind the importance that a conception of a universe ruled by hidden sympathetic relations had hidden on the idea of secrecy prevailing during the fifteenth and sixteenth centuries, and questioning whether there was a dialogue between esoteric currents as the Kabbalah and the hermeticism and the design of mechanisms created by Della Porta for use in the techniques of secret communication. Recalling that such techniques were within the passage of the medieval regimen to the modern state, as tools used by the secretaries in their efforts to protect the princely power, that passed from instrument for the salvation of souls into something whose goal rested in himself.

KEY WORDS: Giambattista della Porta; Secret Communication; Magic.

(recebido em 22/01/2013, aprovado em 28/04/2013)

1 Texto baseado em comunicação apresentada no I Colóquio Internacional LEME / VIVARIUM / CEEO: Clérigos e Laicos: interações na Idade Média no Renascimento, realizado entre os dias 27 e 29 de agosto de 2012 na Universidade Federal de Goiás.

2 Mestre e doutorando em História e Culturas Políticas pela Universidade Federal de Minas Gerais. Codiretor do Centro de Estudios sobre el Esoterismo Occidental de la UNASUR Bolsista de Doutorado da FAPEMIG. E-mail: kirijy@gmail.com. 
No ano de 1563, foi publicada a obra De furtivis Literarum Notis vulgo De Ziferis, que constituiu um retorno do napolitano Giambattista della Porta (c. 1535-1615) ao tema da comunicação secreta, após tratar dele em um dos capítulos de sua obra anterior Magiae Naturalis, publicada no ano de 1558. No De Ziferis, Della Porta buscou apresentar uma espécie de manual da comunicação secreta, dedicado às formas de cifrar uma mensagem, bem como de decodificá-la.

Como já havia feito em seu Magiae Naturalis, Della Porta buscou amparo nos textos da Antiguidade para compor sua nova obra.

\begin{abstract}
Quando eu olhava em todo tipo de registro antigo por certos monumentos escritos à mão, de modo que eu pudesse tirar deles alguma coisa secreta e oculta (a natureza tinha me feito sempre inclinado para essas coisas), desde que mais de uma vez eu encontrei certas notações obscuras e caracteres, nos quais escritores [que tinham] aversão [que] seus leitores [tivessem] conhecimento das matérias estão acostumados a esconder seus escritos cuidadosamente, eu fui frequentemente compelido a deixar isso à parte, crescendo, enquanto, [eu ficava] mais ansioso para atingir ao seu significado interior. ${ }^{3}$
\end{abstract}

Por toda a obra, a Antiguidade surgiu como o repositório onde Della Porta retirou não apenas as técnicas de comunicação secreta, mas também a motivação para lidar com elas. Já entre os pensadores da Antiguidade haveria a preocupação de manter certos saberes protegidos de olhares indesejados. A escrita secreta seria então a ferramenta ideal para levar a cabo essa tarefa de proteger tais conhecimentos. Della Porta dessa maneira se inseria numa longa tradição envolvendo o uso do ziferis.

Em seu "Prefácio aos leitores", pode-se perceber um pouco da personalidade do autor. Della Porta se vangloriou seguidamente de suas capacidades intelectuais, o que teve continuidade durante a execução dessa obra. Ele apresentou seu relacionamento com as cifras da comunicação secreta como algo a principio difícil, que teria desanimado muitos homens, mas ele perseverou. E dessa perseverança teriam surgido não apenas uma grande capacidade para decodificar tais mensagens, como também o desejo de compor um livro onde ele poderia organizar todo esse conhecimento acerca do ziferis.

When I was looking in every sort of ancient record for certain monuments written by hand, in order that I might take out from these something secret and hidden (nature has always made me inclined to such things), since more than once I happened on certain obscure notations and characters, in which writers who grudge their readers knowledge of matters are wont carefully to conceal their writings, I was often compelled to lay these aside, growing, the while, the more eager to get at their inner meaning. DELLA PORTA, Giambattista. On Secret Notations for Letters Commonly Called Ciphers. Translated by Etta Shield Preston on the Fabyan estate at the request of Colonel Fabyan, n.d.. p.III 
Mas desde que essa é a natureza do homem, que o que nós mais ansiosamente desejamos nós desejamos mais seriamente na proporção da dificuldade em alcançar isso, por essa razão aconteceu que eu resolvi não desistir da empreitada até [que] eu pudesse interpretar todas as notações desse tipo que ocorreram, nem 0 favor da fortuna falhou em coroar meus esforços. Visto que, como eu cuidadosamente investiguei o significado dos caracteres, sem nenhuma pequena exceção aí, o problema deu-se por vencido tão alegremente que quando eu seriamente devotei-me a essa investigação eu interpretei não umas poucas notações desse tipo. Quando eu tive tempo o bastante para continuar sinceramente minha investigação sobre o resto, desde que o método de interpretação era múltiplo, e foi provado ao comparar vários escritores, eu decidi escrever um livro sobre eles. Eu não sabia muito bem de princípio como fazer isso. No começo, por esse motivo, coletando e classificando material, eu despendi uma grande quantidade de esforço. Finalmente eu coloquei no papel umas poucas regras às quais rapidamente se apresentaram à minha memória, que na busca delas, quando a necessidade surgiu, eu poderia por no problema. Visto que eu não poderia esperar que, através da variedade do objeto, 0 trabalho poderia crescer para um tamanho como este. ${ }^{4}$

Della Porta apresentou por todo esse prefácio a imagem que pretendia passar aos seus possíveis leitores, a de homem altamente capaz intelectualmente e de senhor de um tipo de técnica que, por mais fácil que fosse para ele, tratada mesmo como um descanso mental, seria de difícil manejo pelo homem comum:

As pessoas talvez vejam por meio de quais regras eu prossegui nessas interpretações, e às quais eu coletei durante esses dias quando minha mente, tirando uma folga de preocupações mais pesadas, inclinou-se para estes estudos mais leves, [que] eu decidi em tê-los impressos. ${ }^{5}$

But since the this is the nature of man, that what we eagerly desire we desire more earnestly in proportion to the difficulty of attaining it, for this reason it came about that I resolved no to desist from the undertaking until I could interpret all the notations of this sort that had occurred, nor did the favor of fortune fail to crown my efforts. For, as I carefully investigated the meaning of the characters, with no little exertion therein, the problem yielded so happily that when I seriously devoted myself to this investigation I interpreted not a few notations of this sort. When I had for some time rather earnestly continued my investigation about the rest, since the method of interpreting was manifold, and was proved by comparing many writers, I decided to write a book about them. How to do this, I did not know very well at first. On the beginning, therefore, in collecting and classifying material, I expended a great deal of effort. Finally I committed to paper a few rules which readily presented themselves to my memory, lest in seeking these, when the need arose, I Should be put to trouble. For I did not hope that, through the variety of the subject, the work could grow to such size. DELLA PORTA, nd. p. III

That people may see by what rules I proceeded in these interpretations, and which I had collected during these days when my mind, taking a holiday from more weighty cares, inclined to these lighter studies, I decided to have them printed. DELLA PORTA, nd. p. IV 
Este livro só teria sido publicado por ter acumulado uma imensa fama antes mesmo de ficar pronto, atraindo os pedidos dos amigos pela sua publicação e as investidas dos inimigos, sendo então publicá-lo a melhor forma de sua defesa. A ideia desenhada pelo seu autor é que o De Ziferis seria tão brilhante que se defenderia sozinha dos ataques contra ela dirigidos.

\begin{abstract}
Mas, pensando em que variedade de julgamentos das pessoas e censura dos invejosos, que estão acostumados a experimentar a sagacidade de seu gênio sobre o trabalho dos outros, qualquer um pode ser exposto ao publicar este livro, eu decidi, gentis leitores, manter este trabalho em minhas próprias mãos tempo o bastante para que ele seja publicado completo e com um grande número de outros livros, os nomes dos quais eu dei no índice de minha enciclopédia. Mas eventualmente, por muitas razões, foi necessário mudar meus planos. Pois quando a fama desse livro se espalhou, enquanto ele ainda estava em processo de preparação, parte por causa das muitas boas demandas de meus amigos os quais tem atuado por um tempo devido a um grande desejo de ler o trabalho, e parte movido pelos ataques de meus inimigos, os quais, por causa [que] esta coisa não tinha até agora sido tentada por ninguém, me invejam à honra disso, eu pensei [que] não seria próprio deixar adiar mais a matéria, mas energeticamente apressar a publicação. ${ }^{6}$
\end{abstract}

Em seu "Prefácio aos leitores", ele informou ainda como organizou seu livro:

Eu devo dividir o objeto inteiro em duas partes; nomeadamente, para escrever em cifras e para ler cifras. A primeira eu devotei o primeiro e o segundo livros, para a última, o terceiro e o quarto. Os sinais pelos quais nós indicamos, isto é, semivogais, e mudas, os métodos de fazer isso, de acordo com os preceitos dos antigos e dos modernos, sinais visíveis e aqueles os quais talvez não sejam vistos, formam 0 conteúdo de todo o primeiro livro. Escrituras, às quais, do princípio ao fim escritas completamente, são incompreensíveis ao interceptador, aquelas que podem ser interpretados por trabalho duro, e aquelas os quais não admitem solução, finalmente, aqueles escritos os quais não apenas não podem ser compreendidos, mas não levantarão qualquer suspeita da parte do interceptador, eu tenho mostrado no segundo livro. No terceiro livro seria apropriado dar interpretações dos escritos, e eu dei dois exemplos disso, pelo qual o leitor pode interpretar o resto. Finalmente, no quarto livro, eu arranjei tabelas ao lado das quais palavras que são necessárias

But, on thinking to what varied judgments of people and censure from the envious, Who are wont to try the acumen of their genius on the labors of others, any one would be exposed Who published this book, I decided, gentle readers, to keep this work in my own hands long enough for it to be published complete with a large number of other books, the names of which I have given in the index of my encyclopedia. But at length, for many reasons, it is necessary to change my plan. For when the fame of this book spread abroad, while it was still in process of preparation, partly on account of a good many demands from my friends who had been actuated for some time by a great desire to read the work, and partly moved by the attacks of my enemies, who, because this thing had not hitherto been tried by any one, grudge me the honor of it, I thought it proper not to delay the matter further, but energetically to hurry the publication. DELLA PORTA, nd. p. IV 
podem ser mais facilmente encontradas. Tudo isso ao fim não significa ganhar facilidade e acurácia pode parecer faltar neste negócio. ${ }^{7}$

Antes de esmiuçar as várias técnicas de codificação e decodificação textual, Della Porta optou por discutir a natureza íntima da comunicação secreta. 0 primeiro passo nessa direção foi a apresentação de uma definição para o ziferis que conectava as práticas de segredo da Antiguidade com as técnicas de comunicação cifrada coevas à Della Porta, mais uma vez proporcionando que "os antigos" cobrissem de dignidade e potência as ideias e práticas dos homens do Renascimento.

Homens literários aplicam o termo, sinais secretos, para aqueles caracteres os quais são tão artificiais que eles não podem ser interpretados por nenhum outro que a pessoa à qual o escrito é intencionado. Mas se nós observarmos a matéria corretamente, nós devemos achar que este termo claramente se adapta a estes escritos, aos quais os homens de nosso tempo comumente chamam cifras. Se, então, a partir de uma pesquisa dos restos literários dos antigos, nós talvez formemos alguma conclusão, nós devemos dizer que estes sinais secretos são nada mais que notações por meio das quais nós garantimos o segredo ou a brevidade em transmitir alguma coisa para aqueles que estão familiarizados com nosso método, e àqueles que nós desejamos [que] saibam a matéria em mãos. Além do mais, nós chamamos então notações visto que por predeterminados caracteres elas denotam letras, sílabas, e frases (como Isidoro disse), e chama de volta a mente do leitor para um conhecimento com significados ocultos. Como um resultado disso nós chamamos aqueles que escrevem de notários. ${ }^{8}$

I shall divide the whole subject into two parts; namely, to write in cipher and to read cipher. To the former I have devoted the first and second books, to the latter, the third and fourth. The signs by which we indicate, that is, semivowels, and mutes, the methods of making these, according to the precepts of the ancients and moderns, visible signs and those which may not be seen, form the contents of the entire first book. Writings, which, through inscribed full, are incomprehensible to the intercepter, those which can be interpreted by hard work, and those which do not admit solution, finally, those writings which not only cannot be understood, but will not even arouse any suspicion on the part of the intercepter, I have shown in the second book. In the third book it would be proper to give interpretations of writings, and I have given two examples of this, by which the reader can interpret the rest. Finally, in the fourth book, I have arranged tables by the side of which words that are needed can more easily be found. All this to the end that no means to gain ease and accuracy may seem lacking in this business. IBIDEM. pp. IV-V

Literary men apply the term, secret signs, to those characters which are so contrived that they cannot be interpreted by any other than the person for whom the writing is intended. But if we observe the matter rightly, we shall find that this term clearly suits those writings, which men of our time commonly call ciphers. If, then, from a survey of the literary remains of the ancients, we may form any conclusion, we shall say that these secret signs are nothing but notations through which we secure concealment or brevity in conveying something to those who are acquainted with our method, and whom we wish to know the matter in hand. Moreover, we call then notations because by predetermined characters they denote letters, syllables, and phrases (as Isidore says), and call back the readers' mind to an acquaintance with the inner meanings. As a result of this we call those who write them notaries. DELLA PORTA, nd. $p$. 1 
Após se ocupar em definir ao seu leitor o que seria de fato o ziferis, de maneira que a Antiguidade validasse tal conceito, Della Porta tratou de discutir suas origens. Ele percebeu a comunicação secreta como oriunda das práticas de natureza mágico-religiosa, em que sua função seria salvaguardar os saberes sagrados da impureza do mundo profano e dos perigos representados pelos olhos curiosos dos não iniciados. Porém, ele percebeu uma potencialidade mais ampla para a comunicação secreta. Sem negar suas origens, Della Porta sugeriu a aplicação das técnicas das cifras nas matérias de interesse dos homens de poder, como os cercos e os conclaves papais, uma vez que as informações que circulariam nestes ambientes deveriam ser alvo do mesmo cuidado que os saberes mágico-religiosos.

Mas se olharmos dentro do uso dessas notações, nós devemos acha-las uteis apenas para coisas como as matérias sagradas, segredos religiosos, e as ciências ocultas. A fim de que elas não possam não ser profanadas pelo leigo, por aqueles que não são ainda completamente iniciados nos ritos em questão, e para prevenir que os mistérios secretos não sejam revelados, nossos predecessores tem feito uma prática de ocultar tais assuntos com caracteres desconhecidos e certos dispositivos simbólicos. Então, também, em empreendimentos perigosos e empregos de grande momento, por exemplo, cercos e assaltos sobre fortalezas, em conclaves papais, em intrigas amorosas, e outros interesses desta sorte, nós usamos estes caracteres para segurança. ${ }^{9}$

O Egito Antigo seria o berço das comunicações cifradas, conforme Della Porta. Teria sido lá que os homens devotados ao cultivo das coisas sagradas teriam buscado pela primeira vez salvaguardar seus assuntos mais importantes por meio de uma forma de escrita cujos mistérios fossem impossíveis de serem desvendados por ninguém além dos iniciados. Tais "símbolos sagrados" ou hieróglifos teriam sido revelados aos homens pela própria divindade, como uma forma mais adequada para comunicar sua sabedoria em segurança, livre dos olhares ímpios. Assim, os alicerces da comunicação secreta estariam fincados em solo sagrado, na dádiva da divindade.

Os sacerdotes egípcios, como conta Cornélio Tácito, temendo que seus ritos pudessem ser divulgados, esconderam-nos em hieróglifos e caracteres secretos. religious secrets, and the occult sciences. For in order that they might not be profaned by the laity, by these who are not yet fully initiated in the rites in question, and to prevent hidden mysteries from being revealed, our predecessors have made a practice of concealing such matters with unknown characters and certain symbolic devices. Then, too, in dangerous undertakings and employments of great moment, for example, sieges and assaults upon strongholds, in papal conclaves, in love intrigues, and other affairs of this sort, we use these characters for security. DELLA PORTA, nd. pp. 1-2 
Para representar o utilizável pelos mistérios visíveis, eles pensaram [que seria] impiedade confiar tais assuntos para a escrita tão descuidadamente que elas pudessem ser profanadas pelo comum e pelo rebanho indigno. Portanto eles tinham suas letras comuns para o estudo de todo mundo, mas aquelas [que] eles chamaram sagradas, apenas os sacerdotes sabiam, transmitidas em segredo de pai para filho. Entre os Etíopes, também, dos quais os egípcios parecem ter sido um ramo, todos empregavam os mesmos dispositivos. Eles chamaram as letras desse tipo de gravuras secretas (hieróglifos) porque por meio desses sinais os mistérios sagrados eram transmitidos. Mas existem alguns que acreditam que ao tempo que os egípcios representaram significados por meio de formas animais, o método familiar de escrita tornou-se tão predominante nos tempos mais antigos, que todos os registros da Antiguidade nas colunas às quais estavam colocadas nos templos de Minerva, e os outros deuses, foram inscritas com caracteres deste tipo, é certo. ${ }^{10}$

Uma vez que as cifras teriam origem nos mistérios egípcios, nada mais natural do que o mais famoso profeta dos mistérios egípcios, conhecido como Hermes Trismegistus, ser também tido como um dos mais prodigiosos utilizadores dos hieróglifos. Lembrando que Hermes Trismegistus foi associado ao deus egípcio Thot, que seria a deidade ligada não apenas às artes mágicas como também à escrita. Dessa união entre os mundos da magia e o da escrita nasceria o hieróglifo, a cifra de uso sagrado.

Jâmblico e outros testemunharam que várias colunas deste tipo foram inscritas por Hermes Trismegisto. Mercúrio também é dito ter escrito em hieróglifos um tipo de progresso do peregrino ${ }^{11}$, ou uma introdução aos mistérios divinos, o qual o profeta Bithis depois encontrou em um santuário em um templo na cidade egípcia, à qual eles chamam Sois, e interpretada pelo rei Amon. ${ }^{12}$

10 The Egyptian priests, as Cornelius Tacitus tells, fearing that their rites would be divulged, concealed them in hieroglyphics and secret characters. For in representing the useable by visible mysteries, they thought it impiety to entrust such matters to writing so carelessly that they could be profaned by the common and unworthy herd. Wherefore they had their common letters for everybody to study, but those they called sacred, only the priests knew, handed down in secret from father to son. Among the Ethiopians, too, of whom the Egyptians seem to have been a branch, all employed these same devices. They called letters of this kind sacred carvings (hieroglyphics) because by these signs the sacred mysteries were handed down. But there are some who believe that at the time when the Egyptians represented meanings by animal forms the familiar method of writing had become so prevalent in the most remote times, that all the records of antiquity on the columns which were placed in the temples of Minerva, and the others gods, were inscribed with characters of this sort, is certain. DELLA PORTA, nd. pp. 2-3

11 No original latino a expressão refere-se a um "caminho deificado" (Deificam Viam), a expressão utilizada pela tradutora "pilgrim progress" parece aludir à obra The Pilgrim's Progress from This World to That Which Is to Come, um obra alegórica cristã escrita por John Bunyan e publicada em 1678.

12 lamblichus and others bear witness that many columns of this sort were inscribed by Hermes Trismegistus. Mercury also is said to have written out in hieroglyphics a sort of pilgrim's progress, or introduction to the divine mysteries, which the prophet Bithis afterwards found in a shrine in a temple in the Egyptian city, which they call Sois, and interpreted for king Amon. IBIDEM, nd. p. 3 
Prova dessa marca originária voltada aos temas relativos ao universo do sagrado foram os assuntos aos quais primordialmente se dedicou o uso dos hieróglifos como suporte de escrita, buscando assim preservá-los do olhar daqueles aos quais tal conhecimento era proibido, uma vez que não estariam adequadamente preparados para lidar com ele, por estarem por demais maculados pela vivência no mundo profano.

Nestes obeliscos, também, de Sesostris e Semnofernes, os quais foram levados do Egito para Roma, Plínio e Estrabão registram que uma explicação do universo estava inscrita em caracteres deste tipo. Consequentemente (diz Jâmblico) tão obscuros eram os enigmas da teologia egípcia que eles requeriam a própria musa da filosofia para resolvê-los. Em mistérios deste tipo, uma imitação da natureza do universo e trabalho manual dos deuses, eles revelam certa similitude com as inteligências místicas e ocultas, em indicações simbólicas, e mesmo agora, esculpidas em rochas altas, os mais antigos registros antigos podem ser vistos, como aqueles que eu recordo de interpretar desde então. Para este efeito Lucano escreve, com igual brevidade e erudição: "Os fenícios primeiro ousaram, se nós podemos confiar na tradição, dar permanência sonora em caracteres que eram desconhecidos. Mênfis ainda não havia aprendido a tecer livros de papiro, e apenas em rochas, pássaros, feras, e animais esculpidos preservou línguas mágicas." ${ }^{13}$

No nono capítulo do De Ziferis, Della Porta buscou esmiuçar um pouco mais a natureza dos hieróglifos, estes que seriam a forma mais primitiva de escrita secreta. Os hieróglifos seriam na verdade uma estratégia por meio da qual o texto a ser resguardado seria reescrito, se trocando o alfabeto original por um sistema de imagens capazes de substituir as palavras.

Ainda em outra forma sem fala, nós podemos indicar o que desejamos por
representações de objetos e animais, os quais algumas vezes significam
simples palavras, algumas vezes a ideia completa. Dessa forma nós achamos
[que] os antigos egípcios escreveram, os quais conheciam a natureza dos animais, e,
de acordo com suas qualidades peculiares, representaram ideias por imagens deles.
Era essencial, por conseguinte, conhecer a natureza de todos os animais,

13 On those obelisks, too, of Sesostris and Semnofernes, which were brought from Egypt to Rome, Pliny and Strabo record that an explanation of the universe was inscribed in characters of this kind. Hence (lamblichus says) so obscure are the riddles of Egyptian theology that they require the muse of philosophy herself to solve them. For in mysteries of this sort, in imitation of the nature of the universe and the handwork of the gods, they disclose certain likenesses to the mystical and hidden intelligences, in symbolic indications, and even now, carved on high rocks, the most ancient records of antiquity may be seen, like those that I recall interpreting some time since. To this effect Lucan writes, with equal brevity and erudition: "The Phoenicians first dared, if we can trust tradition, to give sound permanence in characters were then unknown. Memphis had not yet learned to weave papyrus books, and merely on rocks, birds, beasts, and sculptured animals preserved magic tongues." DELLA PORTA, nd. p. 3 
quais qualidades as ideias às quais deveriam ser expressas deveriam de alguma forma parecer. ${ }^{14}$

Dessa forma, os hieróglifos seriam representações de elementos do mundo natural, um conjunto de símbolos que seriam capazes de remeter ao elemento original por alguma de suas características, como no caso dos hieróglifos egípcios e seus significados.

Deste modo os egípcios para representar o mundo retratam uma serpente com sua boca voltada para sua calda, e roendo a mesma para expressar a forma. 0 ano é representado pelo sol e pela lua os quais medem o tempo, e o mês por um arco; Deus por um falcão; o destino por uma estrela; a lua e os equinócios por um macaco cinocéfalo; a coragem proeminente por um leão; o coração por uma íbis; a mutabilidade por uma fênix. Os egípcios denotam outras coisas de uma forma similar pelo escaravelho, o dragão, e outros animais (como contou Maneto em seu epítome de ciência natural, e Hecateu em seu primeiro livro de filosofia). ${ }^{15}$

Della Porta ofereceu um exemplo de como se daria a construção de um hieróglifo, desde a escolha da imagem até as atribuições de significado e uso no cotidiano. Ele afirmou que o hipopótamo poderia representar a ingratidão e a perversidade, isso porque quando ele atingisse a maturidade se lançaria em confronto com seu pai e caso o vencesse pouparia sua vida, mas tomaria sua própria mãe como consorte. No caso do pai derrotado não permitir que tal ocorresse, o filho o mataria de forma impiedosa a fim de tomar sua mãe por companheira. Dessa imagem teria surgido o costume de confeccionar o cetro dos reis egípcios com uma cegonha em cima e um hipopótamo embaixo, pois a cegonha seria o símbolo da equidade e da piedade, e o hipopótamo o símbolo da injustiça ${ }^{16}$.

Os hieróglifos teriam uma função essencial de proteger determinados saberes dos olhos e mentes dos sujeitos aos quais se havia considerado impróprios de tomar deles conhecimento. É

$14 \quad$ In yet another way without speech, we can indicate what we wish by representations of objects and animals, which sometimes signify single words, sometimes a whole idea. In this manner we find the ancient Egyptians wrote, who knew the nature of all animals, and, according to their peculiar qualities, represented ideas by pictures of them. It was essential, therefore, to know the nature of all animals, whose qualities the ideas which were to be expressed seemed in some way to resemble. DELLA PORTA, nd. p. 28 (Grifos nossos)

15 Thus the Egyptians to represent the world depict a serpent with its mouth turned back to its tail, and gnawing the same to express the form. The year is represented by the sun and moon which measure time, and the month by a bow; God by a hawk; fate by a star; the moon and the equinoxes by a dog-headed ape; preeminent courage by a lion; the heart by an ibis; mutability by a phoenix. The Egyptians denote other things in a similar manner by the scarab, the dragon, and other animals (as Manethus tells us in his epitome of natural science, and Hecatateus in his first book on philosophy). IBIDEM. p. 29 
interessante que apesar do napolitano indicar usos importantes e pertinentes para a linguagem secreta em relação aos assuntos do mundo profano, ele remete frequentemente ao caráter místico da "notação secreta", como quando sugere que quanto mais uma informação deve ser inacessível ao vulgo, mais interessante seria codificá-la por meio de uma imagem de natureza mística, ou ainda em sua insistência de que para a boa realização da comunicação cifrada se faria necessária a presença de um "intérprete iniciado", o que não deixa de remeter à figura do secretarium ${ }^{17}$.

Os hieróglifos não seriam uma exclusividade nem um privilégio único dos egípcios, eles apareceriam desde a Antiguidade até os dias de Della Porta em várias sociedades, por vezes organizados em livros de segredo protegidos a todo custo, porém também se fariam presentes como adornos de portais, escudos ou mesmo nos elmos dos cavaleiros.

Sobre isso se tem o ainda existente livro de Horus Apollo $^{18}$ sobre os ritos secretos e as gravuras míticas dos egípcios, e 0 livro recente de Petrus Valerius sobre 0 mesmo assunto. Aqui talvez sejam classificados os emblemas e dispositivos pelos quais frequentemente paredes, forcas, painéis, portas e escudos, são decorados, com os quais também as cabeças dos cavaleiros são regularmente marcadas em inclinação nos festivais, os quais pessoas comuns chamam "cimei" mas Alciatus chama emblema. ${ }^{19}$

Dada à importância das mensagens que protegiam e carregavam, era necessário que os hieróglifos estivessem envoltos pela névoa da obscuridade, enganando olhares indesejados. Porém, a obscuridade não poderia ser tanta que impedisse que tais segredos fossem recuperados por aqueles a quem fosse de direito.

Mas dispositivos deste tipo não deveriam ser feitos tão obscuros que eles sempre precisem [de] Apolo para interpretá-los, mas às vezes eles devem ser feitos claros para a mais comum das pessoas. Por essa razão palavras são frequentemente adicionadas a uma gravura em explicação, com receio da obscuridade da figura

18 Provavelmente o autor se refere ao grego Horapollo, autor de Hieroglyphica. É interessante também a alusão ao deus egípcio Horus e ao deus grego Apolo, ambas divindades celestes.

19 On these there is extant the book of Horus Apollo on the sacred rites and the mystic engravings of the Egyptians, and the recent book of Petrus Valerius in the same subject. Here may be classed the emblems and devices by which often walls, hangings, panels, doors, and shields, are decorated, with which also the heads of knights are regularly marked in tilting at the festivals, which common folk call "cimei" but Alciatus calls emblem. IBIDEM. p. 29 
estorvar o grande entusiasmo dos espectadores para compreendê-la. Dessa classe são aqueles os quais são discutidos por Jovius em seu livro de emblemas. ${ }^{20}$

Lemonnier (1997: 145,147) alertou que os hieróglifos egípcios foram descobertos no Ocidente por volta de 1419, mais especificamente através do descobrimento da obra grega Hieroglyphica de Horapollo, por Cristoforo Buondelmonti. Ela afirma ainda que os homens do Renascimento receberam os hieróglifos como signos naturais, ou seja, uma forma de se retornar a linguagem pura de antes da Queda. Os hieróglifos seriam os detentores do segredo dos deuses, colocando-os assim numa perspectiva esotérica. Ela ainda afirma que os hieróglifos tiveram um papel marcante no nascimento da comunicação secreta forjada pelos humanistas, algo que pode ser percebido na obra de Della Porta.

Em uma época marcada pelo visual, os hieróglifos suscitaram uma voga pelos símbolos enigmáticos que não tardaram a dar nascimento ao gênero emblemático, sistematização de um modo de pensamento e de expressão que repousa sobre a elaboração e a decriptação de mensagens codificadas. Pretendendo ser um equivalente moderno dos hieróglifos, os emblemas repousam, portanto como eles sobre a relação entre código, mensagem e recepção e se devem ser criptográficos, desde que toda a verdade não pode ser entregue de forma transparente. ${ }^{21}$

A recepção renascentista dos hieróglifos teria se alicerçado na dupla hermetismo e hermenêutica. Conforme Lemonnier ${ }^{22}$, a noção de segredo implicaria primordialmente em um conhecimento pré-existente ao qual se buscaria dissimular, como um "mundo que oculta outro", um tipo de sabedoria que não se permitiria enganar por aparências falaciosas, o que conduziu à noção de criptografia. Assim, o segredo estaria imerso num movimento duplo: o da revelação, a descoberta de uma chave, da explicação do mistério, por parte daquele que busca e, portanto, da hermenêutica; e o

20 But devices of this sort would not be made so obscure that they always need Apollo to interpret them, but at times they can be made clear to the commonest people. For this reason words are often added to a picture in explanation, lest the obscurity of the picture hinder the great eagerness of the beholders to understand it. Of this class are those which are discussed by Jovius in his book on emblems. DELLA PORTA, nd. p. 30

21 Dans une époque marqueé par le visuel, les hiérogliphes suscitent une vogue pour les symboles énigmatiques qui ne tarde pas à donner naissance au genre emblématique, systématisation d'un mode de pensée et d'expression qui repose sur l'élaboration et le déchiffrement de messages codés. Se voulant un équivalent moderne des hiéroglyphes, les emblèmes reposent donc comme eux sur les rapports entre code, message et réception et se doivent d'être cryptiques, puisque toute vérité ne saurait se livrer de manière transparente. LEMONNIER, Delphine. Emblèmes et secret: autour des hiéroglyphes. In: LAROQUE, François (Ed.). Histoire et secret à la Reniassance. Paris: Presses de la Sorbonne Nouvelle, 1997. p. 145 
da codificação, da restrição de acesso de um conhecimento a um pequeno grupo de eleitos e iniciados, senhores da verdade à qual escondem, logo partidários do hermetismo.

Os hieróglifos tiveram grande influência sobre os humanistas e sobre a arte renascentista, uma vez que não havia à época uma clara distinção entre símbolos criados pelo homem e as manifestações sobrenaturais. Desta forma, ao criarem os emblemas, aqueles homens acreditavam apresentar um equivalente moderno para os hieróglifos, retornando assim à linguagem mais pura que desvendava os segredos dos deuses. Ficino apresentou uma boa demonstração dessa ideia ao afirmar que quando os sacerdotes egípcios desejavam dar "significado" aos mistérios divinos, não o faziam por meio dos caracteres comuns, mas por meio das imagens das plantas e dos animais ${ }^{23}$.

Della Porta admitiu que as línguas cifradas tiveram a participação ativa dos magos em sua confecção, pois estes necessitavam também de uma forma de proteger seu conhecimento. Evidenciase aqui mais uma vez a problemática questão de quais seriam as fronteiras entre a religião e a magia, tema amplamente discutido por vasta bibliografia, abrangendo a sociologia, a antropologia e a história. Porém o que a fonte revela é que, para os homens dos séculos XV e XVI essa diferença é tão etérea quanto àquela entre estas áreas da experiência humana e a ciência. $O$ que prevalecia entre tais sujeitos era a relação entre eles e o mundo natural, sendo magia, religião e ciência tão unicamente meios pelos quais se daria tal experiência.

Nós temos visto que os Magi inventaram e moldaram certos caracteres para salvar seu conhecimento do uso ou da leitura da ralé, como qualquer leitor pode ver por si mesmo em Honório Tebano e outros. Apuleio escreve do seguinte modo sobre estes caracteres: "Dos lugares ocultos do santuário ele traz certos livros, escritos em letras desconhecidas. Estes apresentam formas de palavras encurtadas às quais tem um significado especial em imagens de animais deste tipo, e são também protegidas da curiosidade do leigo por marcas peculiares acima delas, algumas vezes torcidas, na forma de uma roda, ou curvadas juntas como os chifres de um bode". ${ }^{24}$

Entretanto, apesar de reconhecer a influência da magia e da religião na composição do ziferis, é oportuno observar que Della Porta relacione entre os principais interessados no uso do ziferis fora do

24 We have seen also that the Magi invented and fashioned certain characters to save their knowledge from use or reading by the rabble, as any reader can see for himself in Honorius Thebanus and others. Apuleius writes as follows about these characters: "From the hidden places of the shrine he brings out certain books, written in unknown letters. These show shortened word forms which have a special meaning in animal characters of this kind, and are also protected from the curiosity of the laity by peculiar marks placed above them, sometimes twisted, wheel shape, or bent together like the horns of a goat". DELLA PORTA, nd. pp. 3-4 
âmbito mágico-religioso como sendo os reis, ainda mais em se tratando de um momento em que o poder real deixava de ser mero instrumento para salvaguardar e proteger as almas do rebanho da Cristandade, como pregava o regimen medieval, para tornar-se um fim em si mesmo, gerando um movimento por sua posse como propriedade da pessoa do rei, e não mais atributo de sua função ${ }^{25}$. Outro tema recorrente nas preocupações dos homens dos séculos XV e XVI surge na argumentação de Della Porta, que tratava dos perigos ofertados pela Fortuna. Essa deusa caprichosa colocava em risco estes conhecimentos e saberes tidos como próprios apenas a um seleto grupo de indivíduos, uma vez que poderia criar situações nas quais ele seria revelado, como quando cartas e mensageiros fossem interceptados. Porém, o ziferis seria uma forma de enganar a Fortuna, de garantir o segredo de tais informações em qualquer que fosse o cenário. A mesma preocupação permeia a obra do abade alemão Johannes Trithemius (1462-1516), que, em sua Steganographia (c.1500), sugeria que se utilizasse a comunicação secreta por meio dos espíritos aéreos, pois eles não seriam corrompidos pela ação da Fortuna, ao contrário do que poderia ocorrer com os mensageiros e com as cartas.

Porque assim como é frequente ser vantajoso para os reis a uma distância de seus ministros anunciarem seus desejos secretos, para maquinadores, ou qualquer pessoa engajada em assuntos deste tipo, nós recorremos ao uso desses caracteres como salvaguarda, então que batedores, salteadores de estradas ou oficiais postados em locais convenientes (para os braços dos reis e príncipes serem longos) [para que] talvez não interceptem nossas cartas e revelem nossos desígnios secretos para seus mestres, especialmente em tempos quando a mais completa licença prevalece, e quando ninguém ousa proibir crimes. Ademais, elas têm sido trazidas para o uso pelo objetivo da brevidade; como, por exemplo, quando alguma coisa tem que ser escrita brevemente e a frequente repetição de palavras e nomes poderia exaurir o leitor, de modo que o que quer que seja requerido pode ser incluído com menos trabalho e em uma forma mais concisa. $E$ assim os muitos que tem atormentado seus cérebros elaborando esses caracteres tem tido alguma justificativa para seus esforços. Suas numerosas invenções nesta direção eu recordarei, cada uma em seu próprio lugar. ${ }^{26}$

25 SENELLART, Michel. As artes de governar: do regimen medieval ao conceito de governo. São Paulo: Editora 34, 2006.

26 For as often as it is advantageous to kings at a distance from their ministers to set forth their secret desires, to plotters, or to any other persons engaged in matters of this kind, we resort to the use of these characters as a safeguard, so that scouts, footpads, or officers posted in convenient places (for the arms of kings and princes are long) may not intercept out letters and reveal our secret designs to their masters, especially in times when the most complete license prevails, and when no one dares to prohibit crimes. Furthermore, they have been brought into use for the sake of brevity; as, for example, when something has to be written briefly and frequent repetition of words and names would exhaust the reader, in order that whatever is required may be included with less labor and in more concise form. And so the many who have racked their brains in devising such characters have had some justification for their efforts. Their numerous contrivances in this direction I will record, each in its proper place. DELLA PORTA, nd. p. 2 
Della Porta pareceu preocupado com a instabilidade do mundo no qual vivia, onde, segundo, ele "prevalecia a mais absoluta licenciosidade". Nesse ambiente, o segredo aparecia como uma forma privilegiada de se proteger a ordem, num cenário em que os crimes e os criminosos the pareciam além de qualquer justiça. Lembre-se de que o autor viveu num momento de grande tensão entre as cidades italianas, o papado e o Império. Sua cidade natal, Nápoles, foi objeto de frequentes disputas, conhecendo vários senhores ao longo da vida de Della Porta. Assim, se justifica o temor do autor napolitano frente à licenciosidade de um tempo sem lei, ou melhor, de um momento em que a lei se mostrava frágil demais aos seus olhos para garantir a ordem. Tendo tudo isso em mente se facilita a compreensão da justificativa que o napolitano propôs para o uso da comunicação cifrada:

Pelo que, ore, pode ser mais vantajoso em grandes questões, quando a traição de planos secretos seria tornar necessário conhecer grandes perigos, que para cada pessoa tomar conta de si mesma não apenas as cartas às quais ele envia não deveriam ser conhecidas, mas que seus subterfúgios não deveriam eles mesmos levantar nenhuma suspeita? Como isso resultará que estes não sejam detectados, ele pode se esquivar dos perigos intermediários e, seu desígnio concluído, fazer bem a sua fuga. Mas para prevenir o uso de tortura para extrair a verdade, é importante que as cartas não sejam interceptadas. Depois de contar alguns novos métodos de compô-las, eu mostrarei por meio de quais táticas alguém pode se proteger contra esse tipo de malogro, e talvez também reconhecer os estratagemas dos outros apontados contra ele mesmo, e reduzi-los à nada, fazer o bem a si mesmo contra todos os desastres de atos de infidelidade. ${ }^{27}$

Como dito anteriormente, haveria inúmeras situações do mundo profano nas quais seria muito útil o emprego da comunicação secreta, como enumerou Giambattista Della Porta: As possíveis aventuras deste tipo são numerosas e importantes. Nessa classe estão as intrigas privadas de amantes e de outros, eleições da Igreja, os desígnios de forças hostis, e muitos outros assuntos deste tipo, no curso dos quais incontáveis acasos e perigos podem ocorrer ${ }^{28}$. 0 uso da "notação privada" nas

27 For what, pray, can be more advantageous in great affairs, when the betrayal of secret plans would necessitate meeting the greatest hazards, than for each person to take care for himself not only that the letters which he sends should not be known, but that his subterfuges should not of themselves arouse any suspicion? Whereby it will result that these being undetected, he can dodge the intermediate dangers and, his design accomplished, make good his escape. But to prevent the use of torture to elicit the truth, it is important that letters should not be intercepted. After telling some new methods of composing these, I will show by what tactics one may guard against such miscarriage, and may also recognize the stratagems of others aimed against himself, and bringing them to naught, make good himself against all disasters of acts of infidelity. DELLA PORTA, nd. p. 9

28 The possible adventures of this kind are numerous and important. In this class are the private intrigues of lovers and others, church elections, the design of hostile forces, and many others matters of this sort, in the course of which countless haps and hazards may occur. IBIDEM. 
comunicações de conteúdo relevante também serviria para proteger os envolvidos dos perigos trazidos pelos volteios caprichosos da Fortuna.

\begin{abstract}
É claro a partir desses exemplos que isto é de grande vantagem para o escritor, e também para a pessoa a quem ele está escrevendo, que os segredos seriam confiados para a escrita com as devidas salvaguardas, pois vários riscos e aberrações da fortuna são prováveis que aconteçam por meio das quais planos secretos talvez caiam nas mãos dos inimigos, e nesse caminho não apenas fazer [com que] os projetos falhem do resultado desejado, mas [que] os autores não escapem impunes. [...] Mas tomaria muito tempo recapitular toda a lista de exemplos espalhados através das incontáveis páginas da história, que claramente anunciam quanto dano cartas escritas sem dissimulação tem feito para os escritores e, por outro lado, quanto tem beneficiado pelas cartas [que] têm sido escondidas. Nós, também, que escrevemos estas linhas, temos com frequência feito a boa fortuna em fazer um serviço aceitável para amigos neste particular. Ao interceptar e interpretar missivas traiçoeiras deste tipo, nós temos salvado nossos amigos de atos de traição, os quais foram preparados, e nos quais eles teriam de outro modo facilmente caído. ${ }^{29}$
\end{abstract}

Della Porta afirmou ter atuado como "secretário de cifras" para amigos, a fim de lhes proteger de ciladas e traições. É uma pena que não tenhamos ainda encontrado documentação que confirme tal informação, e, nesse caso, informe quem seriam tais amigos beneficiados pela expertise do napolitano. A função do secretarium seria muito semelhante a essa que Della Porta afirma ter exercido. Ainda que de fato não tenha atuado na qualidade de secretário de alguém, essa afirmação inserida no bojo de sua obra dá o tom da finalidade para a qual foi pensada.

Della Porta trabalhou também em seu livro com os chamados métodos invisíveis de escrita: Agora nos deixe considerar os métodos de escrita invisíveis, os quais nossa época tem mais habilmente forjado no lugar da anterior ${ }^{30}$, mais uma vez retomando o passado como forma de adquirir potência e ao mesmo tempo num esforço por mostrar que os homens de sua época representariam o

29 It is clear from these examples that it is greatly to the advantage of the writer, and also to that of the person to whon he is writing, that secrets should be entrusted to writing with proper safe-guards, for various chances and freaks of fortune are likely to happen through which secret plans may fall into the hands of enemies, and in this way not only do the projects fail of the desired outcome, but the authors do no escape unpunished. [...] But it would take too long to run over the whole list of examples scattered through the countless pages of history, that clearly show forth how much harm letters written without concealment have done do the writers and, on the other hand, how much it has benefited for letters to have been concealed. We, too, who write these lines, have often had the good fortune to do an acceptable service to friends in this particular. By intercepting and interpreting treacherous missives of this kind, we have saved our friends from acts of treachery, which were preparing, and into which they would otherwise easily have fallen. DELLA PORTA, nd. pp. 11-12

30 Now let us consider the invisible methods of writing, which our age has more cleverly contrived in place of the former. IBIDEM. p. 46 
ápice de um movimento de excelência humano que teria se iniciado na Antiguidade. A escrita invisível apresentava a vantagem de oferecer grande dificuldade de ser decifrada se interceptada antes de chegar às mãos do destinatário, uma vez que seria uma tarefa inglória para aqueles que não conhecessem de antemão os meios pelos quais ela foi decifrada.

\begin{abstract}
Assumamos o método invisível de escrita, porque a menos que um esquema é usado por quem a escrita pode mais tarde ser feita visível, os caracteres escaparão completamente da vista do espectador, então aquele para quem a escrita é destinada deve saber adiantadamente do autor o método de revelação da notação. Isso será vantajoso para o uso desse método de escrita em vez de qualquer outro, porque isso permite grande obscuridade, em questões do maior momento, quando 0 segredo não é de pequena vantagem, especialmente se isto [for] combinado com alguma cifra. ${ }^{31}$
\end{abstract}

A maneira mais segura para se garantir o segredo na comunicação secreta envolveria a aplicação de camadas de linguagem cifrada. De uma forma mais clara, Della Porta sugeria que se utilizassem as técnicas de escrita invisível em conjunto com as cifras. Com isso, a mensagem traria aos olhos do inimigo um duplo desafio: descobrir a própria mensagem, camuflada pelas técnicas de escrita invisível, e, se ele tivesse sido vitorioso nesse desafio, restava-lhe ainda a árdua tarefa de decifrar a mensagem que estaria codificada.

Della Porta classificou os meios de escrita invisível ou secreta como pertencentes ao plano da magia natural, fazendo inclusive uma referência direta à sua obra Magiae Naturalis. Assim, uma vez mais, a comunicação secreta seria devedora de mecanismos mágicos para garantir seu segredo. A justificativa do autor para inserir tais métodos em sua obra, a de que eles foram devidamente testados, trouxe para o âmbito da magia natural a ideia de experimento, algo que era perfeitamente natural para um humanista do século XIV (DELUMEAU, 1983). A experiência é mais uma forma de relação humana com o mundo sensível para os homens do Renascimento, logo, não restringível sob o rótulo de científica, mais aplicável a todos os esforços de compreensão do mundo sensível por meio de sua observação empírica.

31 Let us take up the invisible methods of writing, because unless a scheme is used by which the writing can afterwards be made visible, the characters will altogether escape the sight of the beholder, so that he for whom the writing is destined must have known in advance from the writer the method of disclosing the notation. It will be advantageous to use this method of writing rather than any other, because it affords great obscurity, in affairs of the greatest moment, when concealment is of no small advantage, especially if this combined with some form of cipher. DELLA PORTA, nd. p. 46 
Portanto, que nada talvez possa ter sido omitido, o qual talvez pertença ao presente tópico, em nossa discussão do assunto, nós devemos dar primeiro vários caminhos os quais nós temos transferido de nosso livro sobre magia natural, provado anteriormente por [meio de] experimento. Visto que nada foi estabelecido aqui o qual o resultado não tenha sido primeiro mostrado ser verdadeiro, e não parece inoportuno revisar isso nesse momento, alguns deles são conhecidos de todo menino de escola. ${ }^{32}$

Assim, Della Porta buscou apresentar soluções em escrita invisível que pudessem atender a todas as circunstâncias nas quais fossem aplicadas, independente do período do dia ou mesmo dos recursos que o operador tivesse em mãos.

Cartas são feitas às quais desaparecerão de dia, mas se tornarão visíveis à noite na ausência de luz ou nas trevas. 0 método disto é o seguinte. Pegue arganazes e cuidadosamente extraía o suco deles ainda concordando com as ordens dadas em nosso Magia ${ }^{33}$. Então escreva as notações secretas satisfatoriamente sobre o papel com este líquido. Se nós formos cuidadosos sobre isto os caracteres não serão visíveis de dia, mas à noite eles serão vistos brilhar com uma cor ardente. Outros por outro lado destilam madeira de salgueiro fermentada em água, e escrevem caracteres com este licor que é assim extraído; embora este método de escrita seja elogiado por sua sutileza e não por sua conveniência e utilidade. Pois o trabalho requer excesso de minúcia em sua execução, e você talvez, depois de tudo, tenha seus problemas para suas dores, pois se a escrita é exposta ao fogo por qualquer um que a interceptar, isto será imediatamente revelado. ${ }^{34}$

Abundam os exemplos e as instruções de como empregar as virtudes ocultas dos elementos do mundo natural em função dos propósitos da escrita invisível, buscando colocar os simplicia corpora, ou corpos simples, princípios elementares que regeriam as relações simpáticas no universo, à

32 Wherefore, that nothing may seem to have been omitted, which may pertain to the present subject, in our discussion of the matter, we shall give first several ways which we have transferred from our book on natural magic, proved formerly by experiment. For nothing has been set down there which the result had not first shown to be true, and it does not seem untimely to review these at this point, although some of them are known to every school boy. IBIDEM.

33 Parece-nos que Della Porta não quis dizer "nosso livro sobre magia", mas "quemadmodum in Magia docuimus", ou seja, "como mostramos no Magia", numa referência apenas ao título de sua outra obra.

34 Letters are made which will disappear by day, but become visible at night in the absence of light or in darkness. The method of this is as follows. Catch dormice and carefully extract the juice from them in stills according to the directions given in our book on magic. Then write the secret notations nicely on paper with this liquid. If we are careful about this the characters will not be visible by day, but at night they will seem to glow with fiery color. Others on the other hand distill willow wood fermented in water, and write characters with the liquor that is thus extracted; though this method of writing is to be commended for subtlety rather than for convenience and usefulness. For the work requires over-nicety in execution, and you may, after all, have tour trouble for your pains since if the writing is exposed to fire by any one who intercepts it, it is immediately revealed. DELLA PORTA, nd. pp. 46-47 
disposição da comunicação secreta. Dois exemplos interessantes dessa aplicabilidade das substâncias naturais em prol do segredo envolviam o vinagre e a gordura.

Por outro método, entretanto, nós podemos fazer [com que uma] notação escrita em papel branco, ou qualquer parte do corpo, permaneça oculta, e seja revelada quando for necessário. Deixe a inscrição ser feita sobre o braço ou as costas, ou qualquer outro membro, secretamente com vinagre, ou vinho, e isto seco, de modo que nenhum traço possa ser visto. Para revelar a escrita deixe fuligem, ou papel queimado, ser friccionado sobre, pois assim as letras irão brilhar. Ou de um jeito diferente, se as notações forem desenhadas com banha de porco, ou sebo, ou qualquer outra gordura, ou goma, e então o pó de carvão de papel queimado é polvilhado sobre elas para revelá-las. ${ }^{35}$

Uma vez debatidas as formas de escrita invisível, Della Porta partiu para tratar da comunicação cifrada propriamente dita. Seu primeiro passo foi apresentar uma definição para a cifra, de uma forma que, além de conceitualizá-la, também foi feita uma defesa de seu uso, a partir de sua eficácia na salvaguarda do segredo.

Entregando nossas ideias para a linguagem cifrada (à qual nós propomos especialmente neste volume), nós [não queremos] exprimir nada mais que usando tal artifício na escrita, que o que nós desejamos anunciar em uma carta, nós ocultamos de tal maneira que isto não pode ser interpretado em nenhum outro jeito que aquele usado por nós para enquadrá-lo. Disso resulta que a escrita deste tipo é facilmente compreendida por ninguém que não 0 amigo o qual nós desejamos [que] nossos negócios sejam conhecidos. (DELLA PORTA, nd: 53) ${ }^{36}$

As cifras poderiam ser divididas em três tipos principais, que possuiriam subclasses, e que variariam em conformidade com a ordem, a forma e o valor. Della Porta apresentou os mais diversos métodos para a composição de mensagens secretas envolvendo a substituição de palavras ou letras por números, símbolos ou mesmo outras palavras e letras; mensagens que se comporiam a partir da

35 By another method, however, we can cause notation written on white paper, or any part of the body, to remain hidden, and to be revealed when there is need. Let the inscription be made on the arm or back, or any other member, secretly with vinegar, or wine, and this dried, so that no even a trace can be seen. To disclose the writing let soot, or burned paper, be rubbed on, for thus the letters will shine out. Or in a different way, if the notations are drawn with lard, or tallow, or any other fat, or gum, and then the dust of coal of bumt paper is sprinkled on to reveal it. DELLA PORTA, nd. p. 47

36 By committing our ideas to cipher writing (which we propose especially in this volume), we mean nothing else but using such an artifice in writing, that what we wish to announce in a letter, we conceal in such a manner that it cannot be interpreted in any other way than that which was used by us in framing it. From this it results that writing of this kind is easily understood by no one but the friend by whom we desire our affairs to be known. IBIDEM. p. 53 
seleção combinada de determinadas letras ou sílabas de um texto; ou mesmo pelo uso de artifícios como tabelas e discos de substituição.

Existe, amplamente falando, três classes deste tipo de artifício, para a carta ter três qualidades principais, ordem, forma e valor. Portanto, um método de obscurecer a escrita é pela mudança de ordem; como, se Roma é escrita amor. Outro é por mudança de forma; como se, em lugar das formas de nossas letras, qualquer outra coisa poderia ser escrita à vontade, e esta forma tem um valor compreendido. Deste modo Esdras, o escriba e jurista, (como Jerônimo estabeleceu em seu prefácio para o Livro dos Reis), quando ele estava escrevendo o livro no qual as leis estavam contidas, usou novos caracteres, os quais mais tarde foram recebidos em uso pelos judeus, e na passagem do tempo tornou-se conhecido para todos de modo que não outros caracteres duraram entre os judeus até o momento presente do que aqueles que foram descobertos naquele tempo, e por essa razão obscura. Outro método é por mudança do valor das formas, como se para uma letra dos Tírios uma letra de Palamedes fosse substituída, e por uma de Parlamedes igualmente uma de Simonides de Melos, ou vice-versa. Pois se algum crédito pode ser colocado nos registros dos antigos, os Tírios introduziram dezesseis letras entre os Gregos, depois Palamedes quatro, finalmente Simonides é dito ter adicionado um número igual, de modo que ao todo elas completam o número vinte e quatro. ${ }^{37}$

Ao tratar da natureza e da multiplicidade de formas de se aplicar as cifras na comunicação secreta, Della Porta não deixou de tratar do método proposto pelo abade Johannes Trithemius.

Entre os métodos de cifras os quais estão comumente em uso, o artifício do abade Trithemius é o de uma sutileza que não deve de forma alguma ser desprezada. $\mathrm{Na}$ elaboração deste método ele ao mesmo tempo trabalhou através de quase tudo de um grande volume. Antes eu aprendi que este método foi tratado em outro lugar, mas eu estava relutante em passar sobre isto, com receio de que o trabalho em mãos pareça deficiente em algum ponto. As razões para incluí-lo são como se seguem. $O$ assunto pareceu completamente valioso para ser concluído. Este método é valioso para evitar suspeita. Finalmente nós tínhamos executado este método em uma forma diferente e melhor que a original que seu autor desenvolveu, pois enquanto ele reduz o assunto para a forma de um discurso religioso, nós

37 There are, broadly speaking, three classes of such artifices, for a letter happens to have three principal qualities, order, form, and value. Wherefore, one method of obscuring writing is by change or order; as, if Roma is written amor. Another is by change of form; as if, in place of the forms of our letters, anything else we please be written at will, and this form have an understood value. In this way Esdras, the scribe and jurist, (as Jerome states in his preface to the Book of Kings), when he was writing the book in which the laws were contained, used new characters, which afterwards were received into use by the Jews, and in the passing of time became known to all so that no other characters have endured among the Jews until the present time than those which were new discoveries at that time, and for that reason obscure. Another method is by changing the value of the forms, as if for one letter of the Tyrians a letter of Palamedes was substituted, and for one of Palamedes likewise a letter of Simonides of Melos, or vice versa. For if any credence can be placed in the records of the ancients, the Tyrians introduced sixteen letters among the Greeks, afterwards Palamedes four, finally Simonides is said to have added an equal number, so that altogether they complete the number 24. DELLA PORTA, nd. pp. 53-54 
organizamos isto em uma mais conveniente forma de carta, à qual levantará menos suspeita. Além disso, nós adicionamos alfabetos de linhas, pontos, e outros sinais os quais são comumente utilizados em cartas, a fim de que nós evitemos a necessidade de sempre substituir uma palavra por uma letra do alfabeto. Nós temos sido capazes de ganhar brevidade pois nós trabalhamos o método mais elaboradamente do que ele fez. ${ }^{38}$

Della Porta não apenas admitiu ter conhecimento do abade Trithemius e sua obra, bem como teceu sobre ela comentários. Rendeu-lhe elogios, lembrando sua sutileza e eficácia, porém não Ihe poupou críticas, no tocante ao volume de substituições e sinônimos exigidos para se criptografar uma carta, bem como pelo fato do abade ter preferido um formato religioso para suas cartas criptografadas. As críticas ao volume textual que o método do abade implicava não foram uma inovação do napolitano; de fato, ele reproduziu uma das críticas mais frequentes dirigidas a obra de Trithemius. Della Porta chegou mesmo a afirmar que aprimorou o método trithemiano, a fim de que ele se tornasse mais enxuto e eficiente, otimizando suas tabelas de substituição e inserindo mais sinais para a substituição. Porém, ele se omite quanto à polêmica sobre o envolvimento do abade de Sponheim com demonomagia. Ele não comentou a presença na obra do abade dos espíritos aéreos, nem a influência que a astrologia tinha no método esteganográfico, possivelmente influenciada pela obra de Pietro d'Abano (1215-1350) chamada Heptamenron, cuja primeira edição conhecida datava de 1496, logo coeva à Steganographia. Também passou ao largo de suas observações a interessante coincidência dos nomes de alguns dos anjos planetários apresentados por Trithemius e os espíritos da magia salomônica, bem como as referências diretas a Hermes Trismegustus. Enfim, Della Porta não mencionou nenhum dos elementos que relacionavam Trithemius ao universo da magia.

É possível que ele tenha feito tal recorte objetivando manter-se centrado na questão da comunicação secreta, porém tal hipótese se fragiliza uma vez que não se furtou a citar o Trismegistus e mesmo a cabala. Outra explicação tem a ver com a relação do napolitano com a magia. Enquanto 0 abade alemão lidava com uma magia de tipo cerimonial, centrada na relação do mago com os espíritos

38 Among the methods of cipher which are commonly in use, the device of the Abbot Trithemius is of a subtlety by no means to be scorned. In working out this method he at the same time worked through almost all of a huge volume. Before I learned that this method was treated elsewhere I was unwilling to pass over it, lest the work in hand appear deficient in any point. The reasons for including it are as follows. The matter seemed altogether worthy to be included. This method is valuable for avoiding suspicion. Finally we have carried out this same method in a different and better way than its original author evolved, for while he reduce the matter to the form of a religious discourse, we arranged it in the more convenient form of a letter, which will arouse less suspicion. Besides, we have added alphabets of lines, points, and other signs which are commonly used in letters, so that the writing can be briefer, for thus we have avoided the necessity of always substituting a word for one letter of the alphabet. We have been able to gain brevity because we have worked the method out more elaborately than he did. Accordingly let us proceed to the explanation of this method. DELLA PORTA, nd. pp. 110-111 
por meio da relação universal de simpatias, Della Porta lidava com uma forma de magia centrada apenas nesses liames ocultos de simpatia e antipatia, descartando a necessidade de intermediários angélicos ou espirituais. É possível que isso seja uma marca da personalidade de Della Porta, um tipo de homem capaz de "forjar o próprio rosto", que não precisava nem mesmo dos anjos para relacionarse com o próprio Deus, como propunha Pico della Mirandola.

\title{
Considerações Finais
}

Giambattista della Porta foi precursor em diversas áreas do conhecimento humano, como no caso da ótica. Envolveu-se ativamente com os esforços dos homens de seu tempo de melhor compreender o funcionamento do mundo natural, e de como isso poderia ser utilizado em prol das necessidades humanas. Dessa forma, interessou-se pela magia natural, seguindo uma tendência muito forte entre os partidários do humanismo, como, por exemplo, Marsilio Ficino e Pico della Mirandola. Della Porta aplicou os conhecimentos que adquiriu sobre a magia natural para a confecção de métodos de comunicação secreta, envolvendo tanto formas de uma "escrita invisível", bem como as cifras propriamente ditas. Começou essa discussão em um dos capítulos do seu Magiae Naturalis e depois apresentou um extenso tratado sobre o tema, o De furtivis Literarum Notis vulgo De Ziferis, isso num intervalo de tempo de aproximadamente cinco anos. A continuidade entre as duas obras é evidente não apenas pelas impressões intelectuais do autor, mas também pela referência direta e imediata que uma faz a outra.

Ainda em seu prefácio aos leitores, Della Porta renegou que suas práticas em relação à comunicação cifrada fossem de natureza mágica, impressão que surgiria apenas entre os ignorantes, segundo 0 autor.

\begin{abstract}
Mas, quando eu devotei-me zelosamente para este assunto (o qual não pode ser feito apenas pelo trabalho duro?) eu ganhei tal proficiência que em um curto período de tempo eu interpreto cartas de todos os lados e escritas em notações deste tipo ao pedido dos amigos. Por isso eu despertei tal maravilha de mim em suas mentes, que houve pessoas, ignorantes das letras, que pensaram que este poder veio de não outra fonte do que a magia, ou as inspirações de alguma divindade, enquanto, na realidade, a coisa toda estava indicada claramente o suficiente se você considerar o contexto e basear seu julgamento nas regras da ortografia. ${ }^{39}$
\end{abstract}

39 But, when I devoted myself zealously to this matter (what cannot be done by hard work?) I gained such proficiency that in a short time I interpreted letters from all side and written in notations of this sort at the request of friends. By this I roused such wonder of me in their minds, that there were found some persons, ignorant of letters, who thought that this 
Porém, ligou claramente a linguagem cifrada às origens mágico-religiosas, além de diversas vezes recorrer à cabala para confeccionar seus métodos de comunicação secreta. Admitiu que os magos estariam diretamente ligados ao uso destas técnicas, bem como apenas a deidade possuiria meios diretos de conhecer o segredo oculto pelo coração dos homens, restando ao indivíduo devidamente preparado emular tal capacidade ao decriptar uma mensagem. Ainda há seu recurso à magia natural para criar formas de comunicação invisível, cujo uso conjunto com as cifras foi aconselhado para se obter um meio mais perfeito de comunicação secreta, e cujo funcionamento estaria diretamente ligado às relações simpáticas entre os diversos corpos simples que regeriam o universo.

Dessa forma, quando Della Porta afirmou que o poder vinha dele e não de fonte externa, devese à ideia de que o homem seria a medida das coisas, e não uma fonte externa a ele. 0 ser humano em sua máxima potência seria capaz de desvendar o mistério das cifras, que nada mais seria que uma emulação do mistério maior, aquele relativo ao segredo que a deidade ocultou em sua obra maior, o mundo natural. As mesmas ferramentas que seriam empregadas nessa tarefa divina, a cabala e 0 hermetismo, também seriam utilizadas para se ocultar e desvendar os segredos humanos. Assim, as concepções de segredo do homem de cifras e do magus se encontravam, dialogavam e se influenciavam. $O$ segredo que o secretarium buscou resguardar ou desvelar por meio do emprego de suas técnicas estava profundamente alicerçado na ideia do hieróglifo, ou seja, na resignificação do mundo por meio do símbolo. Porém, ao contrário dos egípcios antigos que criam terem-no recebido diretamente dos céus, o homem renascentista o havia esculpido com as próprias mãos, assim como fizera com seu rosto.

\section{Bibliografia}

DELLA PORTA, Giambattista. De Furtivis Literarum Notis vulgo De Ziferis - Libri III. Neapoli: Apud loa Mariam Scotum, 1563.

DELLA PORTA, Giambattista. La magie naturelle ou Les Secrets et Miracles de La Nature. Paris: H. Daraqon, Libraire-Editeur, 1913.

power came to me from no other source than magic, or the inspirations of some divinity, while, as a matter of fact, the whole thing was indicated clearly enough if you considered the context and based your judgment on the rules of orthography. DELLA PORTA, nd. pp. III-IV 
DELLA PORTA, Giambattista. On Secret Notations for Letters Commonly Called Ciphers. Translated by Etta Shield Preston on the Fabyan estate at the request of Colonel Fabyan, n.d.

DELUMEAU, Jean. A civilização do renascimento. V.II. Lisboa: Editorial Estampa, 1983.

DURKHEIM, Emile. As formas elementares da vida religiosa: o sistema totêmico na Australia. São Paulo: Martins Fontes, 1996.

LEMONNIER, Delphine - Emblèmes et secret: autour des hiéroglyphes. In: LAROQUE, François (Ed.). Histoire et secret à la Reniassance. Paris: Presses de la Sorbonne Nouvelle, 1997.

SENELLART, Michel. As artes de governar: do regimen medieval ao conceito de governo. São Paulo: Editora 34, 2006.

TRITHEMIUS, Johannes. Steganographie: Ars per occultam Scripturam animi sui voluntatem absentibus aperiendi certu, 4to, Darmst. 1621. (Written 1500. First printed edition: Frankfurt, 1606.). TRITHEMIUS, Johannes. The steganographia of Johannes Trithemius. Translated by Fiona Tait, Christopher Upton and J.W.H. Walden. Edited, with intro, by Adam McLean. Edinburgh: Magnum Opus Hermetic Sourcebook, 1982. 